2021-09

\title{
Experiences of the Non-religious in
} Psychotherapy: Implications for Clinical

\section{Practice and Therapist Education}

\section{Byrne, J. Stephen}

Byrne, J. S., Lack, C. W., \& Taylor, K. J. (2021). Experiences of the Non-religious in

Psychotherapy, Secular Studies, 3(2), 187-205. https://doi.org/10.1163/25892525-bja10023

Brill

https://doi.org/10.1163/25892525-bja10023

https://libguides.alfred.edu/AURA/termsofuse

This is the Accepted Manuscript of the following article: Byrne, J. S., Lack, C. W., \& Taylor, K. J. (2021). Experiences of the Non-religious in Psychotherapy, Secular Studies, 3(2), 187-205, which has been published in final form at https://doi.org/10.1163/25892525-bja10023.

Downloaded from AURA: Alfred University Research \& Archives 
Byrne, J.S., Lack, C.W., Taylor, K.J. Secular Studies https://doi.org/10.1163/25892525-bja10023

Experiences of the Non-Religious in Psychotherapy: Implications for Clinical Practice and Therapist Education

\begin{abstract}
This study explores the experiences of non-religious clients in psychotherapy, specifically with regard to unwanted religious interventions. Because individuals who identify as non-religious often experience negative judgments of various kinds, they need a safe and accepting therapeutic environment. In the present study, clients expressed that $36 \%$ of therapists reportedly engaged in either unwanted or unhelpful religious discussion, with $29 \%$ explicitly suggesting a religious intervention for their non-religious clients, such as prayer or attendance at church services. For a small percentage of clients, these suggestions led to premature termination. Implications for professional practice, education, and public policy are suggested.
\end{abstract}

Keywords: ethics, atheism, values, secularism, psychotherapy 


\section{Experiences of the Non-Religious in Counseling: Implications for Clinical Practice and}

\section{Counselor Education}

\section{Shifting Demographics}

In approaching clinical work, it is important for mental health providers (MHP) to consider religion and spirituality when navigating the therapeutic relationship and formulating treatment options with clients. A 2017 Gallup poll reported that approximately $78.8 \%$ of Americans identify as religious, with the vast majority of those (73\%) identifying as Christian. Issues related to religion and spirituality have been extensively explored and discussed within the fields of psychology and counseling for decades (Galen \& Kloet 2011). There have been countless empirical studies linking spirituality and religiosity to emotional and psychological well-being, with therapists and psychologists being encouraged to be sensitive to the spiritual needs of religious clients (e.g., Galen \& Kloet 2011).

There has been significantly less research, however, on how to approach working with secular, atheist, and religiously unaffiliated individuals, despite demographic trends showing the number of people identifying as non-religious increasing rapidly and steadily over the past several decades. It is estimated that between $16-23 \%$ of the US population currently identifies as non-religious, an increase of nearly 14\% since 1990 (Pew Research Center 2015; Sahke, 2016). This trend is particularly pronounced among younger Americans, with 32\% of young people aged 18-29 identifying as unaffiliated, as compared with only 9\% of Americans over age 64 (Pew Research Center 2015; Sahker 2016).

In other parts of the world, this trend is even stronger. In many European countries, rates of explicitly non-religious and unaffiliated populations have been increasing for decades. This is 
Byrne, J.S., Lack, C.W., Taylor, K.J. Secular Studies https://doi.org/10.1163/25892525-bja10023

particularly true among nations that skew more politically and culturally liberal, such as the Czech Republic (76.4\%), Netherlands (42\%), Belgium (29\%), France (28\%), Germany (24.7\%), and Sweden (27\%) (Pew Research Center 2012). Furthermore, it is notable that the largest proportions of those identifying as non-religious reside in East Asia, with the vast majority of the populations of China, Japan, Hong Kong, and Korea denying any religious affiliation (Pew Research Center 2012). It is evident that the increase in non-religious identification is not just an American phenomenon, and should therefore be considered within the context of other important multicultural issues.

\section{Prejudice against the Non-Religious}

Despite shifting demographics and a significant increase in the number of individuals identifying as non-religious, there is evidence of ongoing and persistent prejudice against those who identify as atheist and/or secular (Gervais 2013; Swan \& Heesacker 2012). This intolerance is both cultural and political. There is language forbidding atheists from holding public office written into the constitutions of eight of the United States of America - Arkansas, Maryland, Mississippi, North Carolina, Pennsylvania, South Carolina, Tennessee, and Texas (Schwarz 2019). While it is unlikely that any such language would be upheld today, it is reflective of a long history of distrust of non-religious people and a belief that they should not participate in public life (Gervais 2013). Even in states without such laws, non-religious people have historically been excluded from political participation, as a candidate must present him or herself as religious in order to be considered electable. A recent Gallup poll revealed that less than two thirds of Americans would be willing to vote for a well-qualified atheist candidate nominated by their political party (Gallup Organization 2019).

In a frequently cited study, Edgell, Gerteis, \& Hartmann (2006) surveyed participants on 
Byrne, J.S., Lack, C.W., Taylor, K.J. Secular Studies https://doi.org/10.1163/25892525-bja10023 their perceptions of various stigmatized groups, including atheists, homosexuals, Muslims, and other religious and racial minority groups. Data showed that atheists were the most stigmatized population by a wide margin. More than $47 \%$ of respondents reported that they would not approve of their child marrying an individual who identified as atheist, and nearly $40 \%$ reported that they did not believe that atheists "agree with their vision of American society." Other studies have demonstrated that a large portion of the American population hold negative views and stereotypes of non-religious people, including that they are untrustworthy (Gervais, Shariff, et al. 2011), immoral, god-hating (Goodman \& Mueller 2009), angry (Meier et. al. 2015), judgmental, and unlikeable (Gervais 2013). However, the widespread distrust of atheists appears to be most pronounced among those with fundamentalist religious identities (LaBouff \& Ledoux 2016).

This stigma is problematic because it is not limited simply to people's perceptions or stereotypes of the non-religious. Beliefs lead to and inform actions, and as such there are realworld implications for individuals who identify with these groups. . Research has shown that non-religious individuals are perceived as less-deserving of scarce medical resources than individuals belonging to other groups (Furnham, Meader, et al. 1998). It is not surprising, therefore, that many atheists and non-religious people choose to hide their identity rather than sharing it publicly in order to avoid discrimination or exclusion. Zimmerman et al. (2015) compare the experience of "coming out" as atheist within ones' family or community to be similar to that experienced by those who identify as LGBTQ. There is a similar fear of rejection, excommunication, and loss of community support in both populations if they were to let people know who they actually are.

Given how prevalent prejudice toward non-religious people is, it should be unsurprising that there is evidence that these biases can pervade the therapeutic relationship as well, even 
Byrne, J.S., Lack, C.W., Taylor, K.J. Secular Studies https://doi.org/10.1163/25892525-bja10023

though best practices have long dictated that MHPs be open and accepting of the spiritual and religious views of their clients, even when those views may differ (American Counseling Association 2014). As one example, non-religious people report that their lack of supernatural beliefs are often targeted by counselors who themselves hold strong religious beliefs, and that such religious differences between client and therapist can contribute to premature termination (D'Andrea \& Sprenger 2007). Unfortunately, there is a dearth of literature or scholarly material acknowledging non-belief as an important diversity or multicultural issue that MHP need to consider in order to practice ethically (Brewster et al. 2014).

\section{Ethical Mandates and Legal Precedent}

Every major national organization for the mental health professions (including counseling, social work, psychology, psychiatry, and marriage and family therapy) has an ethical mandate against the imposition of the counselor's own personal values upon their clients. Falling under the broad domains of autonomy and nonmaleficence, MHP are expected to be aware of their own personal values, such as those pertaining to religion or spirituality and not misuse their influence. Within the American Counseling Association's (ACA) Code of Ethics, standard A4b directly addresses this, stating that counselors must seek training to avoid this imposition of values, particularly when said values are discriminatory or incongruent with the client's goals for counseling (American Counseling Association 2014). Similarly, the National Association of Social Workers states that "Social workers should not take unfair advantage of any professional relationship or exploit others to further their personal, religious, political, or business interests (National Association of Social Workers 2017).

In recent years, several high-profile court cases, such as Ward v. Wilbanks (2010), Bruff v. North Mississippi Health Services (2001), and Walden v. Centers for Disease Control and 
Byrne, J.S., Lack, C.W., Taylor, K.J. Secular Studies https://doi.org/10.1163/25892525-bja10023

Prevention (2010) have highlighted ongoing concerns regarding counselors imposing their religious values onto their clients. In two cases - Ward v. Wilbanks (2010) and Keeton v. Augusta State University (2011) - a graduate student filed suit, claiming that their dismissals from their respective graduate programs were due to their religious values around homosexuality. However, in each case, a court of law upheld the graduate program's right to require students to adhere to the ACA Code of Ethics (2014).

While these examples were about someone refusing to provide service to a client based on the MHP's religious belief, a different scenario occurs in which a therapist is already engaged in work with a client and then allows their religious belief to have a negative effect on the therapeutic work. Assessment of a client's religious or spiritual values is a practice rooted in multicultural competency, where a client's beliefs are seen as a part of their culture and therefore are an integral part of therapy. However, when these topics are brought up by the MHP when a client has already expressed that they are not interested in discussing them, it may exert undue influence over the client (Cashwell \& Young 2011). Furthermore, anecdotal evidence and experiences of the authors suggest that while formally disallowed, some MHP have in fact used their influence to spread religious beliefs and have used religious interventions with clients who do not want this. In some cases, the client likely does not feel comfortable to disclose their objection, while in others, it may be an obvious conflict. To date, there has been no systematic investigation of these occurrences among any population, but for the non-religious, a group that is often discriminated against already, unwanted religious intervention may further the divide and contribute to worsening outcomes.

\section{Mental Health Needs of the Non-Religious}

In addition to the typical reasons for seeking mental health services (e.g., anxiety, 
Byrne, J.S., Lack, C.W., Taylor, K.J. Secular Studies https://doi.org/10.1163/25892525-bja10023 depression, stress, relationship concerns, and other significant psychiatric conditions), those who are non-religious may have aspects or the impact of their non-religious identity be interwoven into their presenting concern. For instance, the process of deconversion, when someone actively disidentifies with a previous religious or spiritual group, may be (and often is) fraught with stress (Cragun et al. 2012). If the client experiences the loss of a social network due to deconversion, including the loss of approval of family and close friends, this may constitute a major life adjustment. As such, disapproval of one's support network can lead to depression, anxiety, stress, and other difficulties that would either necessitate counseling or further complicate extant issues being addressed. Additionally, intrapsychically, there is a significant adjustment as various core beliefs about one's life, purpose, and values may shift, perhaps significantly. This existential turmoil alone may require professional assistance - the reflections and interpretations of a qualified counselor may be very helpful in helping to navigate one's life post-religion (Winell, 2013).

However, even for a client who is more adjusted in their non-religious identity or feels supported by others, the perceived quality of their psychotherapy may still be affected by the ways in which the MHP, either overtly or subtly, accepts and affirms their non-religious identity or invalidates it. Similar to the ways in which MHP are expected to honor the various identities of our clients with regard to race, ethnicity, gender, sexual orientation, and other aspects of identity, a client's religious or spiritual identity should equally be honored. For instance, if a MHP suggests that the causes or remedies to a client's mental health concerns are rooted in their lack of religious beliefs, this creates a point of disconnection between client and MHP. Further, this flies contrary to some of the most basic counseling skills taught to graduate students, such as empathy and unconditional positive regard (Rogers 1951). To either not acknowledge a client's 
Byrne, J.S., Lack, C.W., Taylor, K.J. Secular Studies https://doi.org/10.1163/25892525-bja10023 worldview and culture or to express one's disagreement with that (via microaggression or macroaggression) violates what Rogers termed "the necessary and sufficient" principles of counseling. As such, the possibility exists that these slights, whether purposeful or not, can lead to early termination, worsening symptoms, or lack of progress in therapy.

But how often do such things occur? And how impactful are they to the therapeutic relationship? This study was conducted to help begin answering those questions, in response to numerous anecdotal accounts that unwanted religious interventions or discussions have led to poor therapy outcomes among non-religious clients. To date, there are no other empirical data to suggest the true prevalence or severity of the issue. The present study sought to remedy this by gaining an understanding of the frequency of such unethical practices, as well as the effects they had on the client. Additionally, the larger mental health field and its training programs need to ensure compliance with existing ethical standards. To some, identity as non-religious is treated as a non-issue, but if the invalidation of this identity leads to poor therapy outcomes or lack of engagement in needed mental health services, our relevant professional organizations and training programs must be held accountable to reeducate and/or censure those responsible.

\section{Method - Procedures and Participants}

Data were collected online via a snowball sampling technique, where a link to the survey was shared first by the researchers via social media. The sample consisted of 333 adults $(72.1 \%$ female) who ranged in age from 20 to 76 years $(M=41.76$ years, $S D=11.49)$, all of whom identified that they had previously seen a mental health provider for therapy. The majority of participants self-identified as white/Caucasian (92.1\%), with 1.1\% African American, 1.1\% Asian, 2.7\% Hispanic, 1.1\% Native American, 0.4\% Native Hawaiian, and $0.9 \%$ of other descent. The vast majority of participants were born in the United States of America (70.5\%), 
Byrne, J.S., Lack, C.W., Taylor, K.J. Secular Studies https://doi.org/10.1163/25892525-bja10023 with another $20.7 \%$ declining to answer that question. The sample had a very high level of education compared to the overall population, with $9.4 \%$ reporting have a doctoral degree, $23.4 \%$ holding a master's degree, $6 \%$ having some graduate work, $30.2 \%$ having an undergraduate degree, $15.5 \%$ having an associate's degree, and 15.5\% having a high school education or some college.

As religious affiliation was a key variable of interest in this project, both current and past religious beliefs were asked about. Current religious affiliation was primarily identified as atheist $(72.8 \%)$ or agnostic $(10.9 \%)$, with smaller numbers identifying as spiritual but not religious $(5.7 \%)$, none $(6.4 \%)$, and other $(4.2 \%)$. The most common past religious affiliations were Protestant (44.5\%), Catholic (18.1\%), and other (11.5\%).

\section{Method - Procedure}

After receiving Institutional Review Board approval for the study, volunteers were recruited via social media, first by the researchers sharing the link in secular or non-religious groups and pages. Snowballing also occurred, as anyone was then free to share the link to the survey either on their personal social media page or on other group pages. No incentive for participation was offered. All data collection took place online via a secure website, with measure completion taking approximately one hour.

\section{Method - Instruments}

Psychotherapy experiences questionnaire. After completing an online consent form, participants were directed to a survey exploring their psychotherapy experiences. Although the consent form and solicitation materials specifically asked for participants with a history of psychotherapy, this question was repeated and individuals who answered 'yes,' were presented with the rest of the survey. For each therapy experience they had, participants were asked to 
Byrne, J.S., Lack, C.W., Taylor, K.J. Secular Studies https://doi.org/10.1163/25892525-bja10023

record the duration in both months and total number of sessions, how long ago the therapy

occurred, and its modality (individual, group, couples, et cetera). Then participants were asked if religious/spiritual topics were discussed in therapy and, if so, to what degree were these acceptable (Likert scale) and helpful (Likert scale). Participants then completed a slightly modified version of the Session Rating Scale (Duncan, et al. 2003), in which they reported on the therapeutic relationship, agreement on goals and topics, thoughts on the approach or method, and their feeling about the overall therapy experience. Minor modifications were made to the wording of the items, so that it referred to the entire therapy experience, rather than a singular session, as it was originally intended. Participants were also asked if their therapist made any suggestions for religious or spiritual interventions and, if so, how they affected the client's perception of the value of therapy (Likert scale) and willingness to seek services again in the future (Likert scale). Next, participants were asked to report that therapist's theoretical orientation (if known; presented with a number of checkboxes) and the primary reason for termination (if not ongoing; presented with a number of checkboxes). Participants were also offered an opportunity to explain any of their answers in an open text box.

Demographics questionnaire. Lastly, participants received a demographic questionnaire with items pertaining to age, sex, gender, sexual orientation, ethnicity, current religious/spiritual identity, past religious/spiritual identity, country of origin, country of residence, level of education, and annual household income.

\section{Results - Mental Health Providers and Therapeutic Contact}

Participants reported seeing a highly variable number of MHP, with most of the sample reporting seeing between 2-4 therapists before. Approximately $40.5 \%$ of the sample were actively seeing a therapist when they participated in this survey. Of the total 868 therapists that 
Byrne, J.S., Lack, C.W., Taylor, K.J. Secular Studies https://doi.org/10.1163/25892525-bja10023 were described in the sample, the majority were described as either practicing a form of cognitive behavioral therapy (34\%; this included "traditional" CBT, dialectical behavior therapy, acceptance and commitment therapy, and eye movement desensitization and reprocessing) or the participants were unsure about the therapist's orientation (36\%). Smaller numbers were described as being eclectic (15\%; employing a combination of two or more modalities), person centered (6\%), or "other" (11\%; a catch all category for those described as practicing psychodynamic, solution-focused, feminist, positive psychology, and more).

\section{Results - Religious Topics in Therapy}

Participants reported discussing religious or spiritual in therapy with over a third of the 868 reported therapists (35.7\%; see Figure 1). The perceived acceptability of those types of topics varied widely, with $21.4 \%$ reporting them to be completely unacceptable/unacceptable, while $57.1 \%$ reported them as acceptable/completely acceptable. In a similar vein, $24.6 \%$ of the sample viewed those discussions as hurtful/very hurtful while another $39.7 \%$ reported them as helpful/very helpful (see Figure 2.).

A substantial minority (29.4\%) of those who had discussed religious topics in therapy reported that their therapist had suggested religious or spiritual interventions such as praying or attending church. Of those, $73.5 \%$ reported that it had a negative or strong negative effect on their perception of the value of therapy, with $55.9 \%$ saying it had negatively or strongly negatively impacted their willingness to seek services again in the future. Correlational analyses further supported this, as those whose therapists did not suggest religious or spiritual interventions reported a much stronger and more positive relationship, as measured by the Session Rating Scale $(\mathrm{r}=.561, \mathrm{p}<0.0001)$. In fact, $7.6 \%$ of the sample reported ending a therapeutic relationship due to unwanted religious suggestions or advice. 
Byrne, J.S., Lack, C.W., Taylor, K.J. Secular Studies https://doi.org/10.1163/25892525-bja10023

Qualitatively, participants who reported having spiritual and religious interventions recommended to them expressed their clear dissatisfaction with that occurring. When asked if they would like to provide more information about this experience, they responded by saying they did not feel understood and respected, that even after explicitly saying they were nonreligious, prayer and going to church were continually suggested, that they were given religionbased self-help books or told to read the Bible, "preached" and proselytized to, and even told they would be going to hell because of their lack of religion (see Appendix A).

\section{Discussion}

The present study indicates that a significant number of non-religious therapy clients have been exposed to unwanted religious messaging from their MHP (see Figure 1), and in some cases, its effects can be quite damaging (see Figure 2), leading to premature termination for 7.6\% of the sample in the present study. In many parts of the world, including the US, clients who do not identify as religious face stereotyping and discrimination. To experience such negative judgments from a licensed MHP, whether consciously intended or not, is a significant problem. The ethical standards of all mental health professions emphasize autonomy and nondiscrimination, which, in these cases, is being stripped away from vulnerable individuals who initially sought counseling or psychotherapy and a place in which they could feel valued and understood. To delegitimize one's non-religious belief system can cause clients to feel badly about the therapeutic relationship and, in some cases, contribute to a worsening of symptoms and reluctance to seek further help. Previously, only anecdotal evidence was available to support this idea, but the present study strongly indicates that unwanted religious messaging and 
Byrne, J.S., Lack, C.W., Taylor, K.J. Secular Studies https://doi.org/10.1163/25892525-bja10023 interventions do occur in counseling at a disturbingly high rate, perhaps even more frequent and intense than originally thought.

The responsibility to address this rests primarily in three places: the graduate programs where mental health clinicians are trained; the state boards that license and oversee such clinicians once they move into the real world and begin practicing; and at an individual level among providers of mental health services. Among practitioners, training programs, and those entities responsible for them, there must be increased focus on ethical practice in this area, just as we have seen an increased shift towards appropriate recognition of and attention to other areas of multicultural competence, such as racial and ethnic identity or sexual orientation and gender issues.

As the initial gatekeepers for those entering a mental health profession, training programs at universities across the nation have a special responsibility to train graduate students in both the legal and practical aspects of ethical practice. Anecdotally, much more attention is paid to respecting the religious views of our clients than is paid to the values and feelings of the nonreligious. Perhaps the non-religious are misunderstood by some practitioners and trainers, but considering the numerous ways illustrated earlier in which the non-religious (especially those who identify as atheist) are discriminated against and judged, our concern is that the lack of attention paid to non-religious issues may be due to more systemic, even sinister, motives. This is especially important for graduate school professors in ethics, multicultural counseling, and practicum/internship/fieldwork classes. One of the roles of such faculty, particular in fieldwork, is that of a gatekeeper, ensuring that only students with a proven track record of competent, ethical practice are allowed to enter the profession. 
Byrne, J.S., Lack, C.W., Taylor, K.J. Secular Studies https://doi.org/10.1163/25892525-bja10023

Graduate programs should pay close attention to the ways in which they are training clinicians to competently and ethically work with religious and non-religious clients. Students must be taught to be aware of potential biases that may affect their clinical work and then strive to eliminate them. Programs should teach strategies for assessment of religiosity that are inclusive of non-religious clients, as well as strategies for ensuring that non-religious clients are made to feel safe. Additionally, being trained to work with more specialized non-religious issues, such as deconversion and its aftermath, is a culturally sensitive practice that ensures that all belief systems are valued, not just the traditional ones in some communities.

The second level of responsibility rests on state licensing boards, who oversee both who can become a practicing mental health clinician and any complaints brought against those in practice. The number of such complaints and their resolutions are not often made public, however, as most state boards do not publish outcomes of disciplinary hearings. While many state licensing boards offer online license verification, there is usually very little detail included. Licensing boards should strongly consider revising their processes for reporting complaints, not just for unwanted religious intervention or proselytizing, but also for all other ethical and legal matters pertaining to psychotherapy. Even the relatively easy step of adding more information on websites about what can be considered unethical practice - such as trying to proselytize to a client - could encourage more reporting of unethical behavior.

In addition, continuing education requirements for license renewal vary significantly from state to state, and sometimes from profession to profession within the same state. For instance, Licensed Mental Health Counselors in New York must present 36 hours of continuing education over three years for license renewal, but psychologists in that same state have no requirement at all for continuing education. Some states specify that a certain number of 
Byrne, J.S., Lack, C.W., Taylor, K.J. Secular Studies https://doi.org/10.1163/25892525-bja10023

continuing education hours must be in ethics, but for others, the requirement is only for a certain

number of hours of some sort of education. Licensing boards should focus on ensuring that clinicians are not just meeting criteria for becoming a practitioner, but for staying up to date and ethical in one's work.

Finally, each mental health provider bears a huge amount of individual responsibility in this realm. While the problem of unwanted religious intervention has been clearly demonstrated by our data, there certainly can be value in the appropriate discussion of religion and spiritual values within a counseling session - even for the non-religious. For many clients, regardless of their identification, these religious or spiritual beliefs shape their views of the world, themselves, and others. These beliefs are worldview data that can inform the therapy session, and like any other form of multiculturalism, are part of a deeper understanding of the client. At times, religious or spiritual identification and community can be a helpful guidepost for struggling clients and a link to other supportive individuals. However, for those clients whose beliefs and/or identification are different than their peers, family, and community, this is not the case, and contrary to the advice of some MHP listed in Appendix A, joining one of these religious groups or churches is simply not the answer to those clients' problems. In fact, this may increase and perpetuate the issues for which they initially sought remediation.

Monitoring ethical compliance is a significant challenge with established professionals who are already licensed for independent practice. The potential for a MHP to engage in unwanted proselytizing is very real. Without a formal complaint to a licensing board, typically by a client but potentially by a fellow MHP, this type of unethical practice may never be challenged. The present study suggests that a client making a formal complaint regarding maltreatment due to a lack of religious beliefs is rare, despite the high number of occurrences. 
Byrne, J.S., Lack, C.W., Taylor, K.J. Secular Studies https://doi.org/10.1163/25892525-bja10023

Instead, these clients are more prone to prematurely terminate therapy and potentially be less likely to seek help again, even if still experiencing distress.

The present study has a number of important limitations to note. In terms of race and education, the sample was not necessarily representative of the United States in general. This sample had a much higher level of education and was predominantly white, so generalizability to the broader population should be done cautiously. At the same time, these groups are those more likely to seek therapy, so it may represent the help-seeking population fairly well. Furthermore, while $90 \%$ of the sample was from the US, the remainder resided in other countries throughout North America, Europe, and Africa, likely a byproduct of the snowball sampling techniques employed by the researchers. Additionally, many of the participants were already open enough about their non-religious identities that they were part of some explicitly secular online groups. It may be that the current study describes more fully those who are "out" in their identity as nonreligious and not as much for those who are either questioning their identity or do not feel comfortable publicly declaring their non-religious belief system. Conversely, it may also be that these troubling trends toward unwanted religious intervention are indeed occurring among less educated counseling clients in other regions as well. These individuals, due to lack of acceptance in their communities and families, may not feel as comfortable being open in their identities, and though less likely to have been forwarded this survey, are still out there in the world, feeling as if a mental health professional has invalidated an important aspect of themselves.

Some critics of this study may question the importance of this research. To some individuals, even within the mental health fields, our recommendations might be an “overreaction." Can't these clients just find a new therapist? They should just talk about these differences with their therapist, right? This is, essentially, a very privileged position to speak 
Byrne, J.S., Lack, C.W., Taylor, K.J. Secular Studies https://doi.org/10.1163/25892525-bja10023

from. If a client is in a religious majority group, there are many others around them who can validate their identity, their lifestyle, and their personhood. But for a client who has been discriminated against personally or at a societal level, abandoned by their family and community, or otherwise treated as an outsider against their will, having a MHP who is accepting, validating, and comforting can be the difference between successful therapy or a more negative outcome. For some, such as a suicidal client seeking help for the first time, this is quite literally a difference of life and death.

Our professions have been paying increased attention to issues of multiculturalism around race and sexual orientation, but there is still significant growth needed with regard to non-religious identification. Ethical practitioners would not tell an African American client that she is overreacting to claims of institutional racism. We ethically would not, and fortunately in many locales are legally prohibited to, attempt to change the sexual orientation of a client who identifies as gay or lesbian. So why do some MHP feel entitled to suggest that their particular brand of religion is what a client needs? Independent practitioners need to monitor themselves and confront peers who are doing this. Graduate programs must take their roles as gatekeepers very seriously in this regard. Regulatory agencies must respond quickly and appropriately to instances of counselors failing to practice ethically with this segment of the population. We must do better. The wellbeing and livelihoods of America's fastest growing identity group is at stake.

\section{References}

American Counseling Association. 2014. ACA code of ethics. Alexandria, VA: Author.

Brewster, M. E., Robinson, M. A., Sandil, R., Esposito, J., \& Geiger, E. 2014. Arrantly Absent. The Counseling Psychologist, 42(5), 628-663. doi:10.1177/0011000014528051 
Byrne, J.S., Lack, C.W., Taylor, K.J. Secular Studies https://doi.org/10.1163/25892525-bja10023

Bruff v. North Mississippi Health Services, 244 F.3d 495 ( $5^{\text {th }}$ Cir. 2001).

Cashwell, C.S. \& Young, J.S. (Eds.). 2011. Integrating spirituality and religion into counseling: A guide to competent practice ( ${ }^{\text {nd }}$ ed.). Alexandria, VA: American Counseling Association.

Cragun, R. T., Kosmin, B., Keysar, A., Hammer, J. H., \& Nielsen, M. 2012. On the receiving end: Discrimination toward the non-religious in the United States. Journal of Contemporary Religion, 27, 105-127. http://dx.doi.org/10.1080/13537903.2012.642741

D'Andrea, L.,M., \& Sprenger, J. 2007. Atheism and nonspirituality as diversity issues in counseling. Counseling and Values, 51(2), 149-158

Duncan, B.L, Miller, S.D., Sparks, J.A., Claud, D.A., Reynolds, L.R., Brown, J., \& Johnson, L.D. 2003. The Session Rating Scale: Preliminary psychometric properties of a "working" alliance measure. Journal of Brief Therapy, 3(1), 3-12.

Edgell, P., Gerteis, J., \& Hartmann, D. 2006. Atheists as "other": Moral boundaries and cultural membership in American society. American Sociological Review, 71(2), 211-234. doi:10.1177/000312240607100203

Furnham, A., Meader, N., \& McClelland, A. 1998. Factors affecting nonmedical participants' allocation of scarce medical resources. Journal of Social Behavior and Personality, 13(4), 735.

Galen, L.W. \& Kloet, J.D. 2011. Mental well-being in the religious and the non-religious: Evidence for a curvilinear relationship. Mental Health, Religion \& Culture. 14(7), 673689. 
Byrne, J.S., Lack, C.W., Taylor, K.J. Secular Studies https://doi.org/10.1163/25892525-bja10023

Gallup Organization. 2019, May 9. Less Than Half in U.S. Would Vote for a Socialist for President. https://news.gallup.com/poll/254120/less-half-vote-socialist-president.aspx

Gervais, W. M. 2013. In godlessness we distrust: Using social psychology to solve the puzzle of Anti-atheist prejudice. Social and Personality Psychology Compass, 7(6), 366-377. doi:10.1111/spc3.12035

Gervais, W. M., Shariff, A. F., \& Norenzayan, A. 2011. Do you believe in atheists? Distrust is central to anti-atheist prejudice. Journal of Personality and Social Psychology, 101(6), 1189-1206. doi:10.1037/a0025882

Goodman, K. M., \& Mueller, J. A. 2009. Invisible, marginalized, and stigmatized: Understanding and addressing the needs of atheist students. New Directions for Student Services, 2009(125), 55-63. doi:10.1002/ss.308

Keeton v. Anderson-Wiley, et al., U.S. Court of Appeals, $11^{\text {th }}$ Circuit, 664 F3rd 865; 2011 U.A. Aoo. LEXIS 25007; 23 Fla. L. Weekly Fed. C 6472011.

LaBouff, J. P., \& Ledoux, A. M. 2016. Imagining atheists: Reducing fundamental distrust in atheist intergroup attitudes. Psychology of Religion and Spirituality, 8(4), 330-340. doi: $10.1037 /$ rel0000066

Meier, B. P., Fetterman, A. K., Robinson, M. D., \& Lappas, C. M. 2015. The myth of the angry atheist. The Journal of Psychology, 149(3), 219-238. doi:10.1080/00223980.2013.866929

National Association of Social Workers. 1999. Code of ethics of the National Association of Social Workers. Washington, DC. NASW Press. 
Byrne, J.S., Lack, C.W., Taylor, K.J. Secular Studies https://doi.org/10.1163/25892525-bja10023

Pew Research Center 2012. The Global Religious Landscape. Retrieved from https://www.pewforum.org/2012/12/18/global-religious-landscape-exec/

Pew Research Center 2015. America's Changing Religious Landscape. Retrieved from http://www.pewforum.org/religious-landscape-study/

Rogers, C.R. 1951. Client-centered therapy: Its current practice, implications, and theory. Boston, MA: Houghton Mifflin.

Sahker, E. 2016. Therapy with the nonreligious: Ethical and clinical considerations. Professional Psychology: Research and Practice, 47(4), 295-302. doi:10.1037/pro0000087

Schwarz, H. 2019, April 23. There are states where you technically can't hold public office if you're an atheist. The Washington Post. https://www.washingtonpost.com/blogs/govbeat/wp/2014/07/08/there-are-states-whereyou-technically-cant-hold-public-office-if-youre-an-atheist/.

Swan, L. K., \& Heesacker, M. 2012. Anti-atheist bias in the United States: Testing two critical assumptions. Secularism and Nonreligion, 1, 32-42. doi:10.5334/snr.ac

Walden v. Centers for Disease Control and Prevention. No. 1:08-cv-02278-JEC U.S. District Court for the Northern District of Georgia, March 18. 2010.

Ward v. Wilbanks. 2010. U.S. Dist. LEXIS 127038 (E.D. Mich., July 26, 2010). Retrieved from http://www.lexisnexis.com

Winell, M. 2013. Leaving the fold: A guide for former fundamentalists and others leaving their religion. Apocyphile Press, Berkeley, CA. 
Byrne, J.S., Lack, C.W., Taylor, K.J. Secular Studies https://doi.org/10.1163/25892525-bja10023

Zimmerman, K. J., Smith, J. M., Simonson, K., \& Myers, B. W. 2015. Familial relationship outcomes of coming out as an atheist. Secularism and Nonreligion, 4(1) doi:10.5334/snr.aw

Figure 1. Acceptability of religious topics in session

\section{Acceptability of Religious Topics}

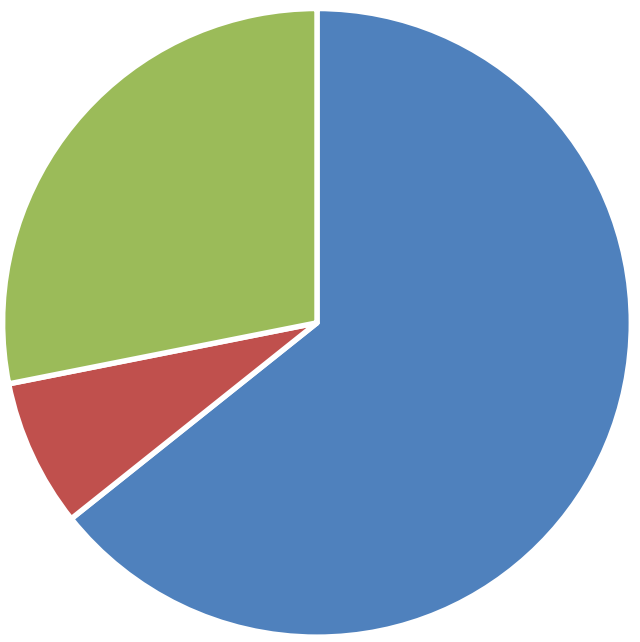

- Topic not discussed - Topic discussed and unacceptable = Topic discussed and neutral or acceptable 
Byrne, J.S., Lack, C.W., Taylor, K.J. Secular Studies https://doi.org/10.1163/25892525-bja10023

Figure 2. Hurtfulness of religious topics in session

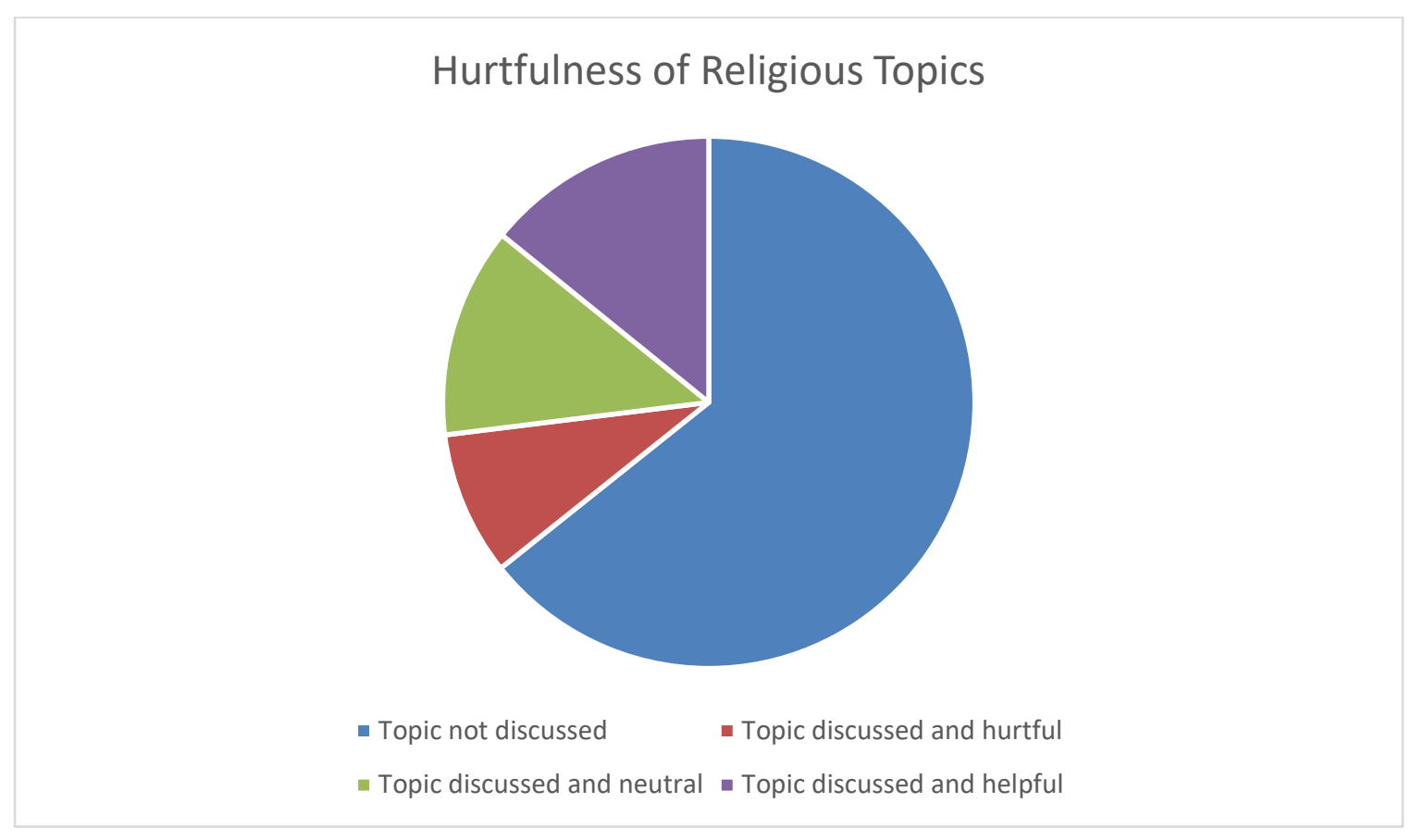

Appendix A. Free Responses Regarding Therapists Suggesting Religious or Spiritual Interventions

- Several therapists suggested in the past or strongly hinted about having some sort of spiritual group or belief. They did not seem to care what I chose. But that was not help to me as I have been an atheist since I was about 12 years old.

- I didn't feel understood or respected.

- I felt it devalued those of us who had different beliefs. I also get that by coming out as different, the other patients and even some nursing staff would try to proselytize. Add this was inpatient care, I felt that this was taking advantage of a vulnerable people, rather than using well 
Byrne, J.S., Lack, C.W., Taylor, K.J. Secular Studies https://doi.org/10.1163/25892525-bja10023 researched therapy modalities (like CBT) for patients. At least stop the other patients from bullying those by allowing people to be preached at.

- Even after being told I was not religious and had no interest in religion, my therapist continued to 'advise' that I pray and/or attend church service.

- She knew I was an atheist, but would suggest things of a spiritual nature and speak metaphorically on whatever it was.

- I was prescribed depression/anxiety medication while hospitalized. The hospital set up my follow-up with a psychiatrist. That psychiatrist had 2 counselors in her office. She required that I see a counselor, and suggested those in her practice. It was the most convenient, even though I knew they were Christian-based and I was not Christian. It turned me off that they did not inquire about my religious beliefs or lack thereof. As the sessions went on, they heavily 'prescribed' Christian practices, such as prayer and attendance at church services. It made me feel like there was no scientific basis for their treatment. I only continued as long as I did so I could continue to see the psychiatrist for med adjustments through a very difficult phase of my life.

- She kept suggesting that I needed to find a higher power.

- Therapist recommended that I see the movie "Fireproof", a religious film; then "get on my knees" to get my ex wife back.

- It was completely irrelevant to my issue and given my history with religion (therapist was aware) more hurtful than helpful

- Since some of my reasons for needing therapy was due to "spiritual abuse" I felt that I was not being heard properly due to bias 
Byrne, J.S., Lack, C.W., Taylor, K.J. Secular Studies https://doi.org/10.1163/25892525-bja10023

- I was expected to read religious based 'self help' material. He tried to make me feel like I disappointed him when I tried to explain that I was not religious. Kept trying to push the reading material on me.

- I still believe therapy has a place but if your therapist gets judgmental about your lack of religion or tells you to try it again it loses value for me because then the therapist is focused on the wrong solutions or problems.

- I told her I was not religious and she kept bringing up as the reason I was struggling and not what I came to talk about.

- The licensed therapist told me: that $\mathrm{i}$ would be judged by my maker when $\mathrm{i}$ told her $\mathrm{i}$ was atheist.

- The bad experience I had was with a male therapist who, after I said I was an atheist, proselytized me and told me I needed to get right with Jesus and that I was 'too smart' for my own good.

- Spouse came back from inpatient substance treatment, he had personal counselor. We decided it would be good to see a separate therapist together. We sat down in her office and it was terrible from beginning. By the end we heard about how her son had died 15 years previously and how she felt "the weight" of his soul leave his body. Her requirement for us was that we be "at least spiritual" as that is part of our humanity that needs to "be fed." Never went back because 1) we talked more about her, 2) even after my husband said he was an atheist, she said only way to recover is to include spirituality.

- I only saw the therapist one time once I left inpatient treatment. She said that she would not talk about religion if I didn't want to, but she talked about it anyways. It was a very dimly lit room 
Byrne, J.S., Lack, C.W., Taylor, K.J. Secular Studies https://doi.org/10.1163/25892525-bja10023

with comfy couches like you're in someone's house. The whole experience made me extremely uncomfortable.

- I was forced by my parents to see a Christian 'therapist' who basically told me that 'God' was testing me like 1 Paul's thorn in the flesh. That I needed to focus solely on him and deny my flesh, puck up my cross and suffer for Christ. It was disturbing and bleak and left me feeling like I was being punished not tested.

- She was kind and wanted to help, but she was inexperienced in my particular set of issues, and all her methods/suggestions always started from a belief in the supernatural, and a being/beings who were the source of help and healing.

- First visit wanted to pray for guidance

- The therapist was informed at the outset that I wanted a therapy process completely free of religious content, but she seemed totally unaware of how ubiquitous her references one. She believed that putting a line through bible verses on the handouts she gave me fulfilled my request. Her Christian viewpoint transcended every aspect of her communications.

- The therapist recommended that I pray for my sister who had stolen drugs from my cancerstricken niece. I found this completely unhelpful.

- This therapist listed themselves as gay friendly and then actively advocated my return to the Church to rid myself of the 'toxic effects of my lifestyle.'

- She used guilt to try to get me to rediscover my faith.

- I didn't feel understood or respected.

- I sought therapy for myself after my father's death. I was 24 and had just spent the past year and a half being the primary caregiver while he was dying of cancer. I was desperate, depressed and couldn't do anything without crying. This therapist waited till I had already opened up to her 
Byrne, J.S., Lack, C.W., Taylor, K.J. Secular Studies https://doi.org/10.1163/25892525-bja10023 after a few sessions and then gave me a biblical book about grief. She told me to give it a try. I was shocked and confused that this therapist would give me a religious text when her business does not state anywhere it is Christian-based. On my next session this therapist asked me what I thought about the book. I said I was not Christian so it didn't help me whatsoever. She suggested I get a Bible and read that so I could understand it better. It was almost humiliating to be put in that spot after opening up to a stranger and trusting them.

- I wanted her to ask me the realistic hard questions. I wanted to solve my problems practically, not cease to think, by 'giving it to God'!

- The first therapist said religion was what I needed (even though my parents religion was the problem). I saw this 2nd therapist years later, my religion changed, and i needed to have, help surviving life as a new mother as my parents disowned me because of religion. The therapist (identified as agnostic) recommended Unitarian Universalist church. Best idea ever. Surrounded by like minded people, I moved from angry atheist to just atheist.

- I'm an atheist, and explained that at the outset. Therapist assured me it would not be an issue in spite of his own religious convictions. He lied: he began and ended our last session explaining that, because I was not a 'believer' nothing remained for us to do together.

- I specifically said I was an atheist before our first session. He took it as a challenge. He was an asshole.

- I have a lot of trauma from my religious experiences. My first therapist suggested I deal with it by going to church and doing some blood-type based diet. It took me a long time to trust a therapist again. Now I'm seeing someone fantastic who can help me explore my previous trauma in a secular context. 
Byrne, J.S., Lack, C.W., Taylor, K.J. Secular Studies https://doi.org/10.1163/25892525-bja10023

- The first marriage counselor that my husband and I went to see was very religious to the point of being offensive, even offensive to my husband who is a religious person and we only saw that counselor once

- My father molested my sister then took off. My mom put me and my sister in 'therapy'. I didn't know what molestation was and just wondered where my dad went. Instead of helping me with this. I was told I needed to pay for my father's soul so he wouldn't burn in hell, for my sister so her purity would be restored in the eyes of God and that my mom needed me to be strong for her because she was struggling. I left feeling like my sister did something wrong, that my dad was going to burn and I shouldn't cry or act sass in front of mom because I was supposed to be a good girl. For 2 years this was pounded into my head every two weeks from the age of 7-9.

- I felt like I'd failed

- The lady told me my OCD was a failure on my part to accept Jesus and let him control my life. I went once \& thought it stunk.

- This first therapist was the worst. Blatant Christian drivel.

- This was a counselor I saw through [identifying information removed]. And he used his platform to shame me into attending his church and demean me for not agreeing with his religion. I reported him to the office manager and was told that I was lucky to get "free" counseling at all.

- One therapist mislead me about her religious orientation. I was told she was spiritual. We were beginning to be effective at tapping into some core issues with EMDR. During one session I began to feel deeply the pain of my cult indoctrination wounds and feeling like I was getting there when she abruptly stopped looking like she was scared $\mathrm{i}$ was denouncing my religious brainwashing. Over the next several sessions I asked her if we could go back and work on what 
Byrne, J.S., Lack, C.W., Taylor, K.J. Secular Studies https://doi.org/10.1163/25892525-bja10023 we tapped into - that i really feel $i$ was on to something but she didn't take me there again. I feel like that set me back. I will only talk to non-Christian counselors. My current one is Buddhist. 